\title{
Collective construction of bundle for immunobiological agents conservation best practices
}

\author{
Construção coletiva de bundle para boas práticas de conservação de imunobiológicos \\ Construcción colectiva de bundle para buenas prácticas de conservación de inmunobiológicos
}

Valéria Conceição de Oliveira'
ORCID: 0000-0003-2606-9754
Patrícia Peres de Oliveira'
ORCID: 0000-0002-3025-5034

Larissa Carvalho de Castro' ORCID: 0000-0001-8676-1350

Heloiza Maria Siqueira Rennó' ORCID: 0000-0002-8142-9313

Dayane Taís de Almeida Gonçalves' ORCID: 0000-0003-2129-6958

Ione Carvalho Pinto" ORCID: 0000-0001-7541-5591

'Universidade Federal de São João del Rei, Divinópolis, Minas Gerais, Brasil "Universidade de São Paulo, Escola de Enfermagem de Ribeirão Preto, Ribeirão Preto, São Paulo, Brasil

How to cite this article: Oliveira VC, Oliveira PP, Castro LC, Rennó HMS, Gonçalves DTA, Pinto IC. Collective construction of bundle for immunobiological agents conservation best practices. Rev Bras Enferm. 2019;72(3):671-9. doi: http://dx.doi.org/10.1590/0034-7167-2018-0406

Corresponding Author: Valéria Conceição de Oliveira E-mail:valeriaoliveira@ufsj.edu.br

Submission: 06-15-2018 Approval: 09-23-2018

\section{ABSTRACT}

Objective: to construct collectively with nursing professionals bundle for best practices of cold chain maintenance of immunobiological agents conservation at the local level. Method: a qualitative research of convergent care type. Bundle construction was guided by the Evidence-Based Practice criterion. Data collection was carried out from October to December 2016, through five workshops, with the participation of 21 professionals from 7 vaccination rooms of a municipality of Minas Gerais State. The framework developed by Morse and Field was adopted for data analysis. Results: through bundle, care is taken regarding refrigeration equipment temperature monitoring, contingency plan performance, recyclable ice coil setting and chamber use as refrigeration equipment. Final considerations: the chosen interventions began to guide the practice and promote a care based on safety and quality.

Descriptors: Evidence-Based Nursing; Immunization; Vaccines; Refrigeration; Nursing Care.

\section{RESUMO}

Objetivo: construir coletivamente, com profissionais de enfermagem, bundle para boas práticas de manutenção da cadeia de frio de conservação de imunobiológicos em nível local. Método: pesquisa qualitativa do tipo convergente assistencial. A construção do bundle foi norteada pelos critérios da Prática Baseada em Evidências. A coleta de dados foi realizada no período de outubro a dezembro de 2016, por meio de cinco oficinas, com a participação de 21 profissionais de 7 salas de vacinação de um município de Minas Gerais. Para análise dos dados, adotou-se o referencial de Morse e Field. Resultados: por meio do bundle, contemplam-se cuidados relativos ao monitoramento da temperatura do equipamento de refrigeração, execução do plano de contingência, ambientação da bobina de gelo reciclável e o uso da câmara como equipamento de refrigeração. Considerações finais: as intervenções eleitas passaram a nortear a prática e promover um cuidado pautado na segurança e qualidade.

Descritores: Enfermagem Baseada em Evidências; Imunização; Vacinas; Refrigeração; Cuidados de Enfermagem.

\section{RESUMEN}

Objectivo: construir colectivamente, con profesionales de enfermería, bundle para buenas prácticas de mantenimiento de la cadena de frío de conservación de inmunobiológicos a nivel local. Método: investigación cualitativa del tipo convergente asistencial. La construcción del bundle fue guiada por los criterios de la Práctica Basada en Evidencias. La recolección de datos fue realizada en el período de octubre a diciembre de 2016, por medio de cinco talleres, con la participación de 21 profesionales de 7 salas de vacunación de un municipio del estado de Minas Gerais. Para el análisis de los datos, se adoptó el referencial de Morse y Field. Resultados: por medio del bundle, se contemplan cuidados relativos al monitoreo de la temperatura del equipo de refrigeración, ejecución del plan de contingencia, ambientación de la bobina de hielo reciclable y el uso de la cámara como equipo de refrigeración. Consideraciones finales: las intervenciones elegidas pasaron a guiar la práctica y promover un cuidado pautado en la seguridad y calidad.

Descriptores: Enfermería Basada en Evidencias; Inmunización; Vacunas; Refrigeración; Atención de Enfermería. 


\section{INTRODUCTION}

Brazil's National Immunization Program (NIP) is comparable to that of developed countries ${ }^{(1)}$. Its complexity is increasing because, in a short time, numerous vaccines were introduced in the routine schedule, including combined vaccines. Vaccines supply already provided until recently has been expanded to population groups not included in the program ${ }^{(2)}$. Such progress shows irrefragable improvements. However, there are intrinsic challenges to the success and increase of NIP, such as homogeneous vaccination coverage maintenance for all vaccines, logistic demands, postvaccination adverse events monitoring, and immunobiological agents conversation chain maintenance.

Thus, in order for the diseases to be controlled or eradicated, it is necessary to guarantee vaccines efficacy by means of strict attention to cold chain maintenance of immunobiological agents conservation; from national to local spheres, where vaccines are administered to people ${ }^{(3)}$. Considering the cold chain process relevance, research has been carried out in order to follow up and evaluate this process, but it was pointed out the need for training of the professionals working at vaccination room at Primary Health Care Units (PHCU) ${ }^{(4-6)}$, as well as the elaboration and implementation of protocols at the local level within the cold network ${ }^{(7)}$.

NIP is an international reference because of its progress in controlling, preventing and eradicating immunopreventable diseases. However, instrumentalization of actions occurs locally and, thus, it is necessary to maintain the immunobiological agents quality administered to the user. An integrative review identified critical events in vaccine conservation in Brazil, as well as in various parts of the world, related to the structure and process in vaccination rooms. The lack of staff training was the most cited critical event in the structural dimension; and the most frequent critical event in the vaccine retention process was the lack of adequate monitoring of temperature records of refrigeration equipment ${ }^{(8)}$.

In this sense, this study is justified by the need for standardization of procedures that must be elaborated collectively by nursing professionals to direct their practice, since they will organize and streamline health services by establishing flows. It is emphasized that the absence of actions standardization entails a great variation in the ways of performing actions, which may weaken nursing care.

Thus, it is categorical to plan and carry out nursing interventions in order to improve care results provided to individuals, health problems and life processes. This requires identification of functional and dysfunctional responses, proposition of interventions and evaluation of results obtained ${ }^{(9)}$. In order to describe a set of evidence-based interventions targeting the user/population undergoing care with inherent risks, such as vaccination, the term bundle was developed by the Institute for Healthcare Improvement ${ }^{(10)}$.

Bundles differ from protocols since they are composed of a small set of evidence-based interventions that, when implemented together, improve outcomes for users, ie a cohesive unit of all steps be followed to succeed. The actions are all scientifically proven and therefore accepted and well established ${ }^{(10)}$. With regard to the conventional protocols, these describe, in a detailed way, specific lines of care, integrate in their framework the norms, routines and procedures related to a certain problem or health condition. In addition, in choosing the interventions that should compose a bundle, one takes into account its applicability and the adhesion of the care team, making this tool of great value for the achievement of goals in the short, medium and long term, besides the improvement of care indicators ${ }^{(10-11)}$.

However, building and implementing bundle in care practice is a challenging. In studies, it is advised that these have to be dynamic, built and implemented in conjunction with health professionals, so that there is motivation of all involved, providing continuous assessment of the care provided and the creation of achievable goals ${ }^{(11)}$.

Design and implementation of bundle favor reduction of costs of health services, can reduce stress of the team during work and collaborate for a better quality of care ${ }^{(11-12)}$.

In this context, in order to carry out effective actions to promote safe care in vaccination rooms, the questioning emerged: which interventions do nursing professionals consider relevant to compose a bundle related to cold chain maintenance of immunobiological agents conservation?

\section{OBJECTIVE}

This study aims to build collectively with nursing professionals bundle for best practices of cold chain maintenance of immunobiological agents conservation at the local level.

\section{METHODS}

\section{Ethical aspects}

This study was approved by the Research Ethics Committee with Human Beings from Universidade Federal de São João Del Rei (CEP/UFSJ), under Opinion 1.231.140 and CAAE (Certificate of Presentation for Ethical Consideration) 47997115.2.0000.5545. Participants voluntarily accepted the invitation to participate in the study, signing the Free and Informed Consent Form.

\section{Type of study and theoretical-methodological frameworks}

This is a qualitative research of the convergent type of care, a method that is conceptualized as the explicit recognition of practice, with an emphasis on intersubjectivity and dialogue of the research process as a practice of reality. The Convergent Care Research (PCA - Pesquisa Convergente Assistencial) proposal is based on a situation of practice and, therefore, is directly compatible with the researcher's purpose ${ }^{(13)}$.

Thus, the search for safe and qualified health care begins when difficulties arising from the practice of care provoke transformations in the daily life of those who experience them, requiring the collective construction of a theoretical axis, based on scientific evidence, capable of modifying the observed reality. To this end, researcher must carry out research and scientific research activities ${ }^{(11,13)}$.

\section{Methodological procedures}

The four phases involving PCA were used: design, instrumentation, analysis and interpretation. The conception phase covered the definition of the problem situation of the daily life of the health professional, which needed to be rethought the 
literature review and the definition of the theoretical framework. In the instrumentation phase, the methodological procedures were traced, which included determination of the location, participants, the way of obtaining and recording research data, as well as techniques that supported the analysis and interpretation of the data. The researcher committed to the development of theoretical knowledge used to implement the proposed changes, in addition to seeking subsidies for the effective change in the studied reality. The interpretation phase consisted of analyzing what was acquired ${ }^{(11,13)}$.

In the case of this study, the conception phase arose because researchers verified the lack of standardization in the use of vaccination rooms and the care provided there, since they accompany nursing undergraduate students from a public university in their clinical practice, in different vaccination rooms of the Primary Health Care (PHC) of a municipality of Minas Gerais State. This led researchers together with nurses responsible for $\mathrm{PHC}$ in the municipality setting of this study to agree to the elaboration, together with all nursing professionals who worked in vaccination rooms, of care bundle related to cold chain maintenance of immunobiological agents conservation.

\section{Study setting and research participants}

Participants were personally invited by one of the researchers in the health units. Guests accepted to participate and, thus, participation of 21 nursing professionals from 7 vaccination rooms of the municipality. This totaled the participation of 12 nurses and 9 nursing technicians.

The quantitative of research subjects was defined by intentional sampling based on the inclusion criteria of being an active nursing professional in vaccination room during the research period and working at $\mathrm{PHC}$ for more than six months. Participants previously signed the FICF, always staying one way with each participant and another with the researcher.

\section{Collection and organization of data}

The research was developed in the second half of 2016, and data collection was centralized from October to December 2016.

In view of the first phase of the PCA, documents that established the routines available in vaccination rooms were analyzed. Documentary analysis provided access to information as well as inferences, since it provided specific details ${ }^{(14)}$. Such an analysis makes it possible to review as needed.

Workshop, another strategy used for collecting data, includes meeting people with similar interests, to study and work for the knowledge or deepening of a topic, under the guidance of a specialist ${ }^{(15)}$. Based on this concept, five workshops with an average duration of three hours were developed throughout the study, all recorded with the prior consent of participants and later transcribed in full.

They were performed in a room provided by the Municipal Health Office, mediated by two researchers and registered in a field diary by a student of the Institutional Scholarship Program of Scientific Initiation (PIBIC - Programa Institucional de Bolsas de Iniciação Científica/CNPq/UFSJ). At that time, there was help from another student, who played the role of observer, noting the nonverbal events that permeated discussions.

In the first workshop, researchers introduced themselves, detailed the objectives of the research and presented the FICF. The following were photos of some aspects of vaccination rooms of Basic Health Units (BHU) of the study's municipality, PowerPoint, which allowed the professionals to approach the reality; and encouraged active participation of those involved by looking closely at their daily work. This is a first reading, in which the theme to be worked was inserted or happening in real life. It was the moment when participants involved could look closely at their work practice, choosing aspects that needed to be developed, worked out, reviewed or improved.

In the second workshop, the key points were identified and, to define them, the facilitators/mediators raised questions that led to discussions, contributing to reflections on the topic in question, in this case, nursing procedures used for the care in vaccination room. Participants listed on Kraft paper what was observed within the reality of the service and the following divergent points were raised in the professionals': handling of ice coils, recording of daily temperature control map, reading of cold room thermometer, divergence of conducts towards temperature changes, internal organization of refrigeration equipment, aspects related to biosafety, material and immunobiological disposal, validity identification of immunobiological vials.

In the third workshop, participants discussed the topics raised, the different forms of operationalization and their relationship with the organization of the service and with the health system. At this stage, facilitators explained the Evidence-Based Practice (EBP) and the conservation of immunobiological agents. Each participant was given a printed sheet, with the levels of evidence of the EBP, organized into classification systems, which would be used to compile the bundle. Each participant took on the task of bringing all the scientific evidence related to the assistance for which he was responsible.

In the fourth workshop, solutions were identified for the problems raised. In this workshop, priority was given to the monitoring of refrigeration equipment temperature monitoring, conduct towards changes in temperatures, thermal box organization, setting of recyclable ice coils and use of refrigeration equipment, which were later analyzed in the light of the EBP criteria, which included the initial phase of theorization.

In the fifth workshop, participants involved were encouraged to construct new knowledge to transform the observed reality through the previously planned hypotheses. At that stage, all participants reflected on existing prior knowledge and the apprehension of new knowledge to be applied in their daily lives, in order to include interventions, considering the cost, ease of implementation, material availability and adherence to these measures.

It should be noted that, in EBP, the levels of evidence are organized into classification systems. In this study, the classification proposed by Melnyk ${ }^{(16)}$ was used to organize the levels of evidence in: level I- evidence from a systematic review or meta-analysis of all relevant randomized controlled trials, or from clinical guidelines based on systematic reviews randomized controlled trials; level II - evidence derived from at least one well-designed randomized controlled trial; 
level III - evidence obtained from well-designed clinical trials without randomization; level IV - evidence from well-designed cohort and case-control studies; level $\mathrm{V}$ - evidence from a systematic review of descriptive and qualitative studies; level $\mathrm{VI}$ - evidence derived from a single descriptive or qualitative study; level VII - evidence from the opinion of authorities and/or expert committee reports.

\section{Data analysis}

For the analysis and interpretation of the data the framework developd by Morse and Field ${ }^{(17)}$, recommended by the processors of the PCA methodology ${ }^{(17)}$ was adopted, in which there are four phases: apprehension, synthesis, theorizing and recontextualization. At the analysis stage, the seizure process was carried out, which included collecting and organizing the information, prepared collectively in the workshops.

The synthesis was the study of the obtained information, analyzing associations and variations of the information. From this stage, the care related to refrigeration equipment temperature monitoring, conduct towards changes in temperatures, thermal box organization, setting of recyclable ice coils and use of refrigeration equipment, analyzed in the light of EBP criteria, which included the introductory point of theorization.

Finally, recontextualisation, which included the final phase of the theorizing, was the result of the combination of care chosen by research participants, allowing the creation of the bundle, contextualized to the study setting.

\section{RESULTS}

Of the 21 nursing professionals who participated in the study, only 2 were male. Among nurses, the mean age was 34 years, and the age ranged from 26 to 46 years. The mean time of operation in vaccination room was 7.4 years, ranging from 2 to 16 years; and 8 nurses were admitted by public contest. Among nursing technicians, the mean age was 41.9 years, ranging from 30 to 61 years. Vaccination room lasted from 2 to 10 years, of which 7 were admitted by public contest.

Collective construction enabled actors to perceive active participants in the care performance, generating the co-responsibility of evaluation, guidance and referrals for the resolution of problems that may interfere in the cold chain maintenance of immunobiological agents conservation.
Through reflection in the workshops, the nursing team listed 22 care related to best practices of cold chain maintenance of immunobiological agents conservation at the local level. Care was grouped into five categories, with their respective levels of evidence. In this way, care regarding refrigeration equipment temperature monitoring, conduct towards temperature changes, setting of the recyclable ice coils, thermal box organization and use of refrigeration equipment can be visualized in Chart 1 .

Chart 1 - Categories, care related to best practices of maintaining the cold chain of immunobiological conservation at local level and level of evidence of care. Minas Gerais, Brazil, 2017

\begin{tabular}{|c|c|c|}
\hline Categories & $\begin{array}{l}\text { Care related to best practices of cold chain maintenance of } \\
\text { immunobiological agents conservation at the local level }\end{array}$ & $\begin{array}{l}\text { Level of } \\
\text { evidence }\end{array}$ \\
\hline \multirow{4}{*}{$\begin{array}{l}\text { Refrigeration } \\
\text { equipment } \\
\text { temperature } \\
\text { monitoring }\end{array}$} & $\begin{array}{l}\text { Checking the temperature (maximum/minimum/current moment) } \\
\text { of the refrigerated chamber and thermal boxes and record daily on } \\
\text { the record map for temperature control at least three times a day - } \\
\text { at the beginning, in the middle and at the end of the working day. }\end{array}$ & Level II \\
\hline & $\begin{array}{l}\text { Displaying the temperature control map in an easy-to-view } \\
\text { location, preferably on the side of the refrigeration equipment. }\end{array}$ & Level VII \\
\hline & $\begin{array}{l}\text { Resetting the refrigeration equipment thermometer after } \\
\text { checking the temperatures. }\end{array}$ & Level V \\
\hline & $\begin{array}{l}\text { Performing preventive maintenance of the refrigeration } \\
\text { equipment. }\end{array}$ & Level V \\
\hline \multirow{3}{*}{$\begin{array}{l}\text { Conduct } \\
\text { towards } \\
\text { temperatures } \\
\text { changes }\end{array}$} & Performing the Health Unit contingency plan. & Level VI \\
\hline & $\begin{array}{l}\text { Communicating to the higher authority, completing the } \\
\text { immunobiological exposed to the situation of quality deviation } \\
\text { form, temperature changes out of the recommended range }\left(+2^{\circ} \mathrm{C}\right. \\
\left.\text { and }+8^{\circ} \mathrm{C}\right) \text {. }\end{array}$ & Level VI \\
\hline & $\begin{array}{l}\text { Segregating batches of the immunobiological agents exposed } \\
\text { to temperature changes, identifying and maintaining them at } \\
\text { the appropriate storage temperature }\left(+2^{\circ} \mathrm{C} \text { to }+8^{\circ} \mathrm{C}\right) \text { throughout } \\
\text { communication and analysis process. }\end{array}$ & Level VI \\
\hline \multirow{5}{*}{$\begin{array}{l}\text { Setting of } \\
\text { recyclable ice } \\
\text { coils }\end{array}$} & $\begin{array}{l}\text { Monitoring coils temperature by means of extension cable } \\
\text { thermometer during setting until temperature reaches } 0^{\circ} \mathrm{C} \text {. }\end{array}$ & Level VI \\
\hline & $\begin{array}{l}\text { Waiting temperature reaches } 0^{\circ} \mathrm{C} \text {, dry the coils and dispense } \\
\text { them in the thermal box. }\end{array}$ & Level VI \\
\hline & $\begin{array}{l}\text { Washing, drying and freezing the coils after removal from the } \\
\text { thermal box. }\end{array}$ & Level VII \\
\hline & $\begin{array}{l}\text { Rotating the ice coils; in other words, keep them in the freezer } \\
\text { for at least } 48 \text { hours. }\end{array}$ & Level VII \\
\hline & Periodically checking the lifespan of coils. & Level VII \\
\hline \multirow{4}{*}{$\begin{array}{l}\text { Thermal box } \\
\text { organization }\end{array}$} & $\begin{array}{l}\text { Arranging the coils set in the bottom and the inner walls, } \\
\text { forming a barrier to reduce the speed of heat exchange with the } \\
\text { external environment. }\end{array}$ & Level VI \\
\hline & $\begin{array}{l}\text { Monitoring the thermal box with a maximum and minimum } \\
\text { digital momentary thermometer with extension cable until } \\
\text { it reaches a minimum of }+2^{\circ} \mathrm{C} \text { and only afterwards place the } \\
\text { immunobiological agents. }\end{array}$ & Level VI \\
\hline & Continuously monitoring the temperature of thermal boxes. & Level VI \\
\hline & $\begin{array}{l}\text { Washing and drying the boxes thoroughly at the end of the } \\
\text { working day, keeping them open until completely dry. }\end{array}$ & Level VII \\
\hline \multirow{4}{*}{$\begin{array}{l}\text { Use of } \\
\text { refrigeration } \\
\text { equipment } \\
\text { (chamber) }\end{array}$} & $\begin{array}{l}\text { Organizing immunobiological agents in the equipment's internal } \\
\text { compartments without the need to differentiate distribution of } \\
\text { products by type or compartment. }\end{array}$ & Level VII \\
\hline & Using inventory management with FEFO (First Expire, First Out). & Level II \\
\hline & $\begin{array}{l}\text { Monthly cleaning the equipment, carrying out the re- } \\
\text { management of products stored before the procedure. }\end{array}$ & Level VII \\
\hline & Checking and weekly recording the vaccine inventory. & Level VII \\
\hline
\end{tabular}


There is a need for periodic reviews of the care included in the bundle, as well as evaluation of its use. Nursing professionals recognized the importance of bundle, both for user care and safety, organization and humanization of care.

\section{DISCUSSION}

Care selection by nursing professionals was guided by evidence that proved their efficacy and also by the feasibility of application in vaccination room. Thus, bundle consisted of levels of evidence $\mathrm{II}$ and $\mathrm{VI}$, including: refrigeration equipment temperature monitoring, performance of the Health Unit contingency plan, setting of recyclable ice coils monitored with thermometer and use of chamber as refrigeration equipment. In order to maintain the cold chain of immunobiological conservation, it was highlighted the importance of the commitment in the accomplishment of all the items of the bundle.

Best practices for storage and preservation of immunobiological agents are part of maintenance guarantee of the immunogenic potency of these inputs, conferred by the producing laboratory, and must be ensured through written procedures and practices and understood by all staff working in vaccination room ${ }^{(18)}$. These practices should be based on evidence relevant to the development of the profession, however, most of the time, they happen through empirical knowledge, which makes the practice incipient, due to the technological advances and acquisitions of the caring process ${ }^{(19)}$.

Next, based on the literature, will be discussed the care provided by nursing professionals to compose the bundle.

\section{Refrigeration equipment temperature monitoring}

Temperature monitoring is a critical point in the cold chain maintenance of immunobiological agents conservation. Health professionals handling immunobiological agents at the local health level should have tools to identify problems and, based on the data, take the necessary measures. In the last ten years, improvements in the monitoring of the cold chain have been reported due to new technologies and the implementation of rigorous monitoring techniques ${ }^{(7)}$.

At the monitoring of refrigeration equipment temperature, thermometers of maximum and minimum digital are usually used. However, their use is not considered best practice and, according to current recommendations, their substitution by electronic temperature recorders ${ }^{(5,20-21)}$.

There is evidence that the use of electronic recorders brings highly significant improvement, especially at the local level, as it allows health professionals to identify changes during the day/ night cycle, including weekends and holidays. Thus, the health professional can determine if there have been unacceptable temperature exposures and thus make informed decisions as corrective measures to reduce and/or eliminate cold chain problems $s^{(6,20,22)}$.

Thus, health professionals can determine if there have been unacceptable temperature exposures and thus make informed decisions as corrective measures to reduce and/or eliminate cold chain problems. This indicates that many cases of freezing and decreased potency may go undetected when continuous monitoring is not used, leading to the administration of ineffective immunobiological agents ${ }^{(7)}$.

Although not yet established in the service researched, municipal managers showed possibilities to implement the use of electronic recorders in vaccination rooms of the municipality. As best practices for the monitoring of refrigeration equipment, managers were instituted in the bundle due to consistent recommendations in the literature and the possibility of establishing in the service researched, managers were instructed to check the temperature (maximum/minimum current moment) of the refrigerated chamber and thermal boxes and record daily on the record map for temperature control at least three times a day - at the beginning, in the middle and at the end of the working day; display the temperature control map in an easy-to-view location, preferably on the side of the refrigeration equipment; reset the refrigeration equipment thermometer after opening it and perform preventive maintenance of the refrigeration equipment ${ }^{(7,23-24)}$.

Actions described above are consistent with the Manual de Rede de Frio (freely translated as Cold Net Manual) from the Ministry of Health's NIP and the Centers for Disease Control and Prevention (CDC) guidelines on storage and handling of immunobiological agents ${ }^{(18,23)}$.

Preventive maintenance is paramount in order to reduce the probability of equipment failure and extend the equipment's lifespan; activities are conducted in a systematic manner prior to equipment failure, based on a schedule defined by time, distance, or operating cycles. Inspection and preventive maintenance are performed even when the equipment performs well and includes routinely monitoring the storage temperature of immunobiological agents, temperature control map, recording sheet for internal and external cleaning date of the refrigeration equipment (it needs to be monthly) and inspection of it in an easy-to-view place. At inspection, functionality of the equipment and its safe use is verified, and can be an independent activity, such as temperature monitoring, or conducted as a preventive part to guarantee adequate functionality ${ }^{(23,4)}$.

In this study, two people were chosen to supervise cold chain temperatures as a way of improving supervision and accountability ${ }^{(25)}$. However, due to low scientific evidence (level VI) and the number of professionals in the PHC, double temperature check in all services was not implemented at that time.

\section{Contingency plan performance}

Cold chain equipment can record failures at any time and, in order to reduce the exposure rate of immunobiological agents to adverse temperatures, it is recommended to use the contingency plan for procedures to be followed when refrigeration equipment stops function for any reason ${ }^{(18,23,4)}$. The plan should be appropriate to the needs of each site and should rely, for example, on the use of an alarm system that contacts designated personnel in the event of a power outage; availability of thermal boxes and recyclable ice coils that allow alternative storage; and temperature monitoring or an emergency generator ${ }^{(23,4)}$. The lack of a contingency plan may have contributed to the higher rate of immunobiological agents loss reported during energy failures in Australia ${ }^{(26)}$. 
As previously reported, emergencies may arise outside of business hours, such as, for example, power outages. It should be noted that Standard Operating Protocols (SOP) for storage, handling and transportation of immunobiological agents were also prepared in the event of cold chamber malfunction, power failures, natural disasters or other intercurrences that could compromise storage conditions of vaccines.

In addition to the SOP preparation, bundle practices were established in the bundle to communicate to the higher authority, completing the immunobiological exposed to the situation of quality deviation form, temperature changes out of the recommended range $\left(+2^{\circ} \mathrm{C}\right.$ and $\left.+8^{\circ} \mathrm{C}\right)$; and appropriately segregate batches of the immunobiological agents exposed to temperature changes, identifying and maintaining them at the appropriate storage temperature $\left(+2^{\circ} \mathrm{C}\right.$ to $\left.+8^{\circ} \mathrm{C}\right)$ throughout communication and analysis process.

\section{Setting of recyclable ice coils}

Most of the efforts were directed towards the maintenance of immunobiological agents at lower temperatures throughout the development of national immunization programs. Over the past 15 years, it has been found that immunobiological agents are more stable in heat than they were originally, and freezing is a threat to the integrity of immunobiological agents ${ }^{(6-7)}$.

The new global recommendations aim to minimize exposure to accidental freezing, which is in fact the main threat to the potency of immunobiological agents, compromising its effectiveness ${ }^{(21,27-28)}$. Among these indications is the ice/gel coils setting that precedes the packaging of immunobiological agents in thermal boxes. Freezing risk increases if the ice/gel coils are not properly set up as demonstrated in a study in India that identified that two-thirds of the vaccine vials showed evidence of freezing ${ }^{(27)}$. The presence of ice coils below $0{ }^{\circ} \mathrm{C}$ is one of the main factors for exposure of immunobiological agents to freezing temperatures ${ }^{(18,23)}$.

It should be noted that thermal boxes are used with reusable ice/gel coils, set at $0{ }^{\circ} \mathrm{C}$, during immunobiological agents transport, in routine activities in vaccination rooms, in campaigns and in extramural activities. NIP does not recommend using bar ice or scales for the conservation of immunobiological agents ${ }^{(18)}$. Thermal boxes can only be used to store limited amounts of immunobiological agents and need to be equipped with a properly calibrated thermometer ${ }^{(23)}$ for temperature monitoring ${ }^{(18,23)}$.

Based on national(18) and world-wide ${ }^{(23)}$ recommendations, in order to reduce exposure to accidental freezing, nursing care and bundle researchers' care about the setting of ice coils was: monitor coils temperature by means of extension cable thermometer during setting until temperature reaches $0{ }^{\circ} \mathrm{C}$; wait temperature reaches $0^{\circ} \mathrm{C}$, dry the coils and dispense them in the thermal box; wash, dry and freeze the coils after removal from the thermal box; rotate the ice coils, in other words, keep them in the freezer for at least 48 hours; periodically check the lifespan of coils.

In the daily routine of vaccination room, thermal box organization is directed to storage of immunobiological agents to be used during working day. Professionals working in vaccination room, who participated in the bundle construction, reinforced important activities to avoid exposure of the immunobiological agents to temperatures out of the recommended, mainly cold temperatures: arrange the coils set in the bottom and the inner walls, forming a barrier to reduce the speed of heat exchange with the external environment; monitor the thermal box with a maximum and minimum digital momentary thermometer with extension cable until it reaches a minimum of $+1^{\circ} \mathrm{C}$ and only afterwards place the immunobiological agents; continuously monitor the temperature of thermal boxes.

There is evidence that cold water packs can safely replace the use of ice packs for immunobiological agents transport (except for the oral polio vaccine) without any damage to potency and, at the same time, prevent the freezing of immunobiological agents. A disadvantage of using cold water packs may be the volume of refrigeration required to store cooling water packets. Therefore, volume requirements for the introduction of cold water packaging must be carefully calculated ${ }^{(6,29)}$.

\section{Use of refrigeration equipment (chamber)}

Most middle-income countries have cheaper, home-type refrigerators that are designed to reduce heat exposure primarily; these countries were more effective in this, but less effective in reducing freezing damage. They present significant performance weaknesses that clearly impact the quality of the handling of immunobiological agents, the equipment's lifespan and reliability of the cold chain ${ }^{(22,28,30)}$.

The immunization program of each country needs to have access to high-performance and well-maintained equipment such as refrigerators and cold boxes to ensure the quality of the cold chain of immunobiological agents conservation ${ }^{(30-31)}$. To this end, governments must mobilize resources internally to improve the cold chain's infrastructure, which represents a relatively small cost compared to the protection value of immunobiological agents ${ }^{(30)}$.

In studies, it is proven that there is consensus regarding the recommendation of replacement of domestic refrigerators by refrigerated chambers in all vaccination rooms $s^{(5,23,27-28)}$. Refrigerated chambers' ability to protect against temperature variations out of the recommended, both positive and negative, compared to other types of refrigerators, leads to less loss of immunobiological agents $^{(24)}$. In New Zealand, from 2002 to 2008, a combination of domestic refrigerated refrigerators replacement, education and team training can be attributed to the best quality standards in cold chain management, resulting in considerable savings in immunobiological agents waste estimated at almost US\$ 4 million per year ${ }^{(28)}$.

In the study setting service, all vaccination rooms already have refrigerated chambers for the storage of immunobiological agents and best practices have been implemented for the use of refrigeration equipment, such as the use of equipment exclusively for immunobiological agents storage; organization of immunobiological agents in the equipment's internal compartments without the need to differentiate distribution of products by type or compartment; use of inventory management with FEFO (First Expire, First Out); checking and weekly record of the inventory and monthly cleaning of the equipment, carrying out the re-management of the products stored before the procedure, as recommended in the literature ${ }^{(18,23)}$. 
It is important to note that despite optimal thermal distribution of chilled chambers, their performance during power outages is surprisingly poor. In another study, it was found that refrigerated chambers, especially those with glass doors, rapidly reached $+8^{\circ} \mathrm{C}$ internal temperature between 45 and 140 minutes, while domestic refrigerators were able to maintain the temperature from 60 to 240 minutes ${ }^{(24,32)}$. A no-break or permanently installed generator will be needed to compensate for power outages ${ }^{(32)}$. Absence of an alternative source of energy supply was associated with the exposure of immunobiological agents to not optimal temperatures ${ }^{(4)}$.

It is emphasized that technological advances benefit the care, but it is important to understand the impact of these advances in this process. Hence the need to validate knowledge and produce evidence to support its application ${ }^{(19)}$.

\section{Study limitations}

There was a small number of surveys with better levels of evidence. For the application of best practice, this finding is of concern, since systematic reviews or meta-analyzes of randomized clinical trials are the gold standard in the survey, being at the top of the pyramid (level I).

However, this limitation results in a greater encouragement for new knowledge search and serves as a challenge for the elaboration of researches with better methodological designs in the cold chain maintenance of immunobiological agents conservation.

\section{Contributions to the fields of nursing and health}

In Brazil, the nursing team occupies a prominent position to improve the storage and handling of immunobiological agents practices, adopting recommendations based on evidence and directing the immunization service to reach the proposed results. It is expected that the bundle use may contribute to the improvement of care in vaccination room in the study setting. Nurses have responsibilities and behaviors at work related to vaccination room, such as the systematic action of monitoring in relation to it and the planning of Evidence-Based Nursing interventions, which is always appropriate to their care practice place, taking into account individual characteristics and needs of users.

\section{FINAL CONSIDERATIONS}

Bundle for best practices of immunobiological conservation and storage at the local level, collectively built by nursing professionals, included four basic recommendations: refrigeration equipment temperature monitoring, contingency plan performance, recyclable ice coil setting and chamber use as refrigeration equipment.

Collective bundle construction description validated the importance of the need to increase nursing procedures performance based on scientific evidence of better classification; most of the findings were found at levels of lesser evidence, level VII, evidence from the opinion of authorities and/or expert committee reports.

For this, it is considered that the methodological framework used contributes to reflection and search for scientific validation of the procedures performed in vaccination room, since participants took over the condition of actors of this construction.

Bundle elaboration through problematization of the reality lived by nursing professionals in vaccination room care also corroborated the effective need for Permanent Education, with significant changes in the work process and effective results in the quality of care. Collective participation, involving health service management, should be highlighted for continuity and evaluation of health care improvement through procedures based on scientific evidence.

\section{FUNDING}

Funding agencies: Fundação de Amparo à Pesquisa do Estado de Minas Gerais (Minas Gerais State Agency for Research and Development) and Ministry of Health. Programa de Pesquisa para o SUS - PPSUS (Research Program for SUS) (CBB - APQ-03509-13).

\section{REFERENCES}

1. Silva BS, Coelho HV, Cavalcante RB, Oliveira VC, Guimarães EAA. Evaluation study of the national immunization program information system. Rev Bras Enferm [Internet]. 2018 [cited 2017 Apr 26]; 71( Suppl 1 ):615-24. Available from: https://doi.org/10.1590/0034-7167-2017-0601

2. Bisetto LHL, Ciosak SI. Analysis of adverse events following immunization caused by immunization errors. Rev Bras Enferm [Internet]. 2017 [cited 2017 July 21];70(1):81-9. Available from: https://doi.org/10.1590/0034-7167-2016-0034

3. Kristensen DD, Bartholomew K, Villadiego S, Lorenson K. What vaccine product attributes do immunization program stakeholders value? Results from interviews in six low- and middle-income countries. Vaccine [Internet]. 2016 [cited 2018 Apr 26];34(50):6236-42. Available from: https://doi.org/10.1016/j.vaccine.2016.10.057

4. Yakum MN, Ateudjieu J, Pélagie FR, Walter EA, Watcho P. Factors associated with the exposure of vaccines to adverse temperature conditions: the case of north west region, cameroon. BMC Res Notes [Internet]. 2015 [cited 2018 Jan 18];8:277. Available from: https://doi. org/10.1186/s13104-015-1257-y

5. Thielmann A, Viehmann, A, Weltermann BM. Effectiveness of a web-based education program to improve vaccine storage conditions in primary care (keep cool): study protocol for a randomized controlled trial. Trials [Internet]. 2015 [cited 2017 Jun 16];16:301. Available from: https://doi.org/10.1186/s13063-015-0824-9

6. Kartoglu U, Milstien J. Tools and approaches to ensure quality of vaccines throughout the cold chain. Expert Rev Vaccines [Internet]. 2014 [cited 2018 Jan 16];13(7):843-54. Available from: https://doi.org/10.1586/14760584.2014.923761 
7. Hanson CM, George AM, Sawadogo A, Schreiber B. Is freezing in the vaccine cold chain an ongoing issue? A literature review. Vaccine [Internet]. 2017 [cited 2018 Jan 18];35(17):2127-33. Available from: https://doi.org/10.1016/j.vaccine.2016.09.070

8. Guimarães EAA, Oliveira VC, Oliveira MM, Viegas SMF, Ferreira AP, Dias FCS. Critical events in the maintenance of vaccine conservation. Rev Enferm UFPE Online. [Internet]. 2018 [cited 2018 Aug 20];12(6):1781-9. Available from: https://doi. org/10.5205/1981-8963-v12i6a230909p1781-1789-2018

9. Hickler B, MacDonald NE, Senouci K, Schuh HB. Strategic advisory group of experts on immunization (SAGE) working group on decade of vaccines. Efforts to monitor global progress on individual and community demand for immunization: development of definitions and indicators for the global vaccine action plan strategic objective 2. Vaccine [Internet]. 2017 [cited 2018 Apr 26];35(28):3515-19. Available from: https://doi.org/10.1016/j.vaccine.2017.04.056

10. Institute for Healthcare Improvement. Using Care Bundles to Improve Health Care Quality. IHI Innovation Series white paper [Internet]. Cambridge (MA): Institute for Healthcare Improvement; 2012 [cited 2017 Jul 20]. Available from: http://www.ihi.org/resources/Pages/ IHIWhitePapers/UsingCareBundles.aspx

11. Lopes LD, Rodrigues AB, Brasil DRM, Moreira MMC, Amaral JG, Oliveira PP. Prevention and treatment of mucositis at an oncology outpatient clinic: a collective construction. Texto Contexto Enferm [Internet]. 2016 [cited 2018 Apr 23];25(1):e2060014. Available from: http://dx.doi. org/10.1590/0104-070720160002060014

12. Oliveira FT, Stipp MAC, Silva LD, Frederico M, Duarte SCM. Behavior of the multidisciplinary team about bundle of central venous catheter in intensive care. Esc Anna Nery [Internet]. 2016 [cited 2018 Apr 21];20(1):55-62. Available from: http://dx.doi. org/10.5935/1414-8145.20160008

13. Trentini M, Paim L, Silva DMGV. Pesquisa Convergente Assistencial: delineamento provocador de mudanças nas práticas de saúde. 3 ed. Porto Alegre: Moriá; 2014.

14. Yin RK. Estudo de Caso: Planejamento e métodos. 5 ed. Porto Alegre: Bookman; 2015.

15. Anastasiou LGC, Alves LP. Processos de ensinagem na universidade: pressupostos para as estratégias de trabalho em aula. 5 ed. Joinvile (SC): UNIVILLE; 2005.

16. Melnyk BM, Fineout-Overholt E. Evidence-based practice in nursing \& healthcare: a guide to best practice. 2 ed. Philadelphia: Lippincot Williams \& Wilkins; 2011.

17. Morse JM, Field PA. Qualitative research methods for health professionals. 2 ed. London (UK): Sage;1995.

18. Ministério da Saúde (BR), Secretaria de Vigilância em Saúde, Departamento de Vigilância das Doenças Transmissíveis. Manual de Rede de Frio do Programa Nacional de Imunizações. Transmissíveis. 5 ed. Brasília: Ministério da Saúde; 2017.

19. Pedrosa KKA, Oliveira ICM, Feijão AR, Machado RC. Evidence-based nursing: characteristics of studies in Brazil. Cogitare Enferm [Internet]. 2015 [cited 2018 Mai 05];20(4):728-735. Available from: https://revistas.ufpr.br/cogitare/article/view/40768/26738

20. Kartoğlu U, Nelaj E, Maire D. Improving temperature monitoring in the vaccine cold chain at the periphery: an intervention study using a 30-day electronic refrigerator temperature logger (fridge-tag). Vaccine [Internet]. 2010 [cited 2018 Apr 26];28(24):4065-72. Available from: doi:10.1016/j.vaccine.2010.03.076

21. Long AJ, Hayney MS. Best practices essential for storage and temperature monitoring of refrigerated. J Am Pharm Assoc [Internet]. 2013 [cited 2018 Feb 10];53(6):660-1. Available from: http://dx.doi.org/10.1331/JAPhA.2013.13537

22. Lydon P, Lyndon P, Ouhichi R, Zaffran M. Reducing the loss of vaccines from accidental freezing in the cold chain: The experience of continuous temperature monitoring in Tunisia. Vaccine [Internet]. 2015 [cited 2017 Apr 26];33(7):902-7. Available from: https://doi. org/10.1016/j.vaccine.2014.10.080

23. Centers for Disease Control and Prevention (CDC). Vaccine Storage and Handling Toolkit [Internet]. Atlanta (GA): CDC; Jan 2019 [cited 2019 Mar 12]. Available from: https://www.cdc.gov/vaccines/hcp/admin/storage/toolkit/storage-handling-toolkit.pdf

24. World Health Organization. How to develop a repair and maintenance system for cold chain equipment. Geneva: World Health Organization; 2017. Available from: http://apps.who.int/iris/bitstream/handle/10665/255751/WHO-IVB-17.05-eng.pdf?sequence=1

25. Azira B, Norhayati MN, Norwati D. Optimal temperature of cold chain and its associated factors among general practitioners in kelantan, malaysia. Int J Collab Res Intern Med Public Health [Internet]. 2014 [cited 2018 May 15];6(6):168-79. Available from: http://internalmedicine. imedpub.com/optimal-temperature-of-cold-chain-and-its-associatedfactors-among-general-practitioners-in-kelantan-malaysia. php?aid $=6419$

26. D'Onise, Almond S, MacDonald B, Watson M, Scrimgeour S. Have purpose-built vaccine refrigerators reduced the cost of vaccine losses in South Australia? Aust N Z J Public Health [Internet]. 2012 [cited 2018 May 15];36(6):572-6. Available from: http://dx.doi. org/10.1111/j.1753-6405.2012.00932.x

27. Murhekar MV, Dutta S, Kapoor AN, Bitragunta S, Dodum R, Ghosh P, et al. Frequent exposure to suboptimal temperatures in vaccine cold-chain system in India: results of temperature monitoring in 10 states. Bull World Health Organ [Internet]. 2013 [cited 2018 Jan 25];91(12):906-13. Available from: http://dx.doi.org/10.2471/BLT.13.119974

28. Turner N, Laws A, Roberts L. Assessing the effectiveness of cold chain management for childhood vaccines. J Prim Health Care [Internet]. 2011 [cited 2017 Apr 26];3(4):278-82. Available from: http://dx.doi.org/10.1071/HC11278

29. Kartoglu U, Ganivet S, Guichard S, Aiyer V, Bollen P, Maire D, Altay B. Use of cool water packs to prevent freezing during vaccine 
transportation at the country level. PDA J Pharm Sci Technol [Internet]. 2009 [cited 2018 May 15];63(1):11-26. Available from: https://pdfs. semanticscholar.org/a82c/a49496e4bd534c4c64510a2a8e08382bdec4.pdf

30. Ashok A, Brison M, Tallec Y. Improving cold chain systems: challenges and solutions. Vaccine [Internet]. 2017 [cited 2018 Jan 16];35(17):221723. Available from: https://doi.org/10.1016/j.vaccine.2016.08.045

31. Purssel E. Reviewing the importance of the cold chain in the distribution of vaccines. Br J Community Nurs [Internet]. 2015 [cited 2018 Apr 20];20(10):481-6. Available from: http://dx.doi.org/10.12968/bjcn.2015.20.10.481

32. Colloster MC, Martin N. Vaccine refrigeration: thinking outside of the box. Hum Vaccin Immunother [Internet]. 2014 [cited 2018 Apr 23];10(4):1126-8. Available from: https://doi.org/10.4161/hv.27660 